\title{
ATLANTE

\section{EL USO DIDÁCTICO DE LA HISTORIETA EN LA FORMACIÓN INICIAL DEL PROFESORADO DE CIENCIAS SOCIALES}

Para citar este artículo puede utilizar el siguiente formato:

Jorge Chauca García: "El uso didáctico de la historieta en la formación inicial del profesorado de Ciencias Sociales", Revista Atlante: Cuadernos de Educación y Desarrollo, ISSN: 1989-4155 (vol 13, № 7 octubre-diciembre 2021, pp. 212-226). En línea: https://doi.org/10.51896/atlante/VUQR5431

\section{RESUMEN}

El presente artículo expone una experiencia educativa sostenida durante cuatro años consecutivos en el Máster Universitario en Formación del Profesorado de Secundaria en la especialidad de Ciencias Sociales de la Universidad de Málaga. Tras reflexionar sobre la importancia del cómic en la enseñanza de la Historia, desde un punto de vista teórico sustentado en el estado de la cuestión, muestra los resultados de la investigación educativa implementada gracias a metodologías activas, renovadoras e innovadoras. Los resultados de la muestra son representativos cuantitativa y cualitativamente, aunque en esta etapa de la investigación nos centramos en la primera dimensión sin obviar la segunda, susceptible de ampliación futura. Las conclusiones más destacadas confirman la operatividad del aprendizaje visual, secuencial y narrativo, entre el profesorado de Historia en formación inicial. El cómic fue entendido como método de enseñanza y como recurso didáctico de elaboración propia. La generación de contenidos elaborados grupalmente favoreció diversos elementos, formativos y de estilo, imprescindibles para el docente del siglo XXI. La conexión entre aulas universitarias y de Educación Secundaria por medio del cómic favoreció la formación del docente y facilitó su praxis profesional.

Palabras clave: Educación, cómic, docente, Ciencias sociales y humanas, innovación educativa, aprendizaje activo, recursos educativos, método de formación.

\section{THE DIDACTIC USE OF COMIC IN THE INITIAL TRAINING OF SOCIAL SCIENCES TEACHERS}

\section{ABSTRACT}

This article presents an educational experience sustained for four consecutive years in the University Master's Degree in Secondary Teacher Training in the specialty of Social Sciences at the University of 
Malaga. After reflecting on the importance of comics in the teaching of History, from a theoretical point of view supported by the state of the question, it shows the results of educational research implemented thanks to active and innovative methodologies. The results of the sample are quantitatively and qualitatively representative, although at this stage of the research we focus on the first dimension without ignoring the second, which is susceptible to future expansion. The most outstanding conclusions confirm the operability of visual, sequential and narrative learning among History teachers in initial training. The comic was understood as a teaching method and as a selfmade didactic resource. The generation of content developed in groups favored various elements, like formative and style, essential for the teacher of the XXI century. The connection between university classrooms and Secondary Education through comics favored teacher formation and facilitated their professional practice.

Keywords: Education, comic, teacher, social and human sciences, educational innovation, active learning, educational resources, formation method.

\section{INTRODUCCIÓN}

El alumnado del siglo XXI es nativo digital, de ahí la necesidad de trabajar con las Nuevas Tecnologías de la Información y la Comunicación (TIC) para desarrollar una docencia competente e innovadora, así como responder educativamente a los intereses y motivaciones de aulas diversas por definición. Respecto a la traslación de esta línea de actuación pedagógica a la formación inicial del profesorado en ESO y Bachillerato, la herramienta Campus Virtual (CV) en el ámbito universitario resulta relevante para unos docentes en formación. La competencia clave "Aprender a aprender", esto es, la autonomía del aprendizaje del alumnado es hoy indiscutible, y en ello tienen mucho que aportar las TIC (Berenguel, 2011; Onieva, 2015). No pasa así con la competencia específica del profesorado que por analogía llamamos "Enseñar a enseñar". De los tres niveles de concreción curricular, el último es el campo abierto al desarrollo del estilo docente y a la aplicación de metodologías activas. Tras la normativa que marca un contexto general, prescriptivo y teórico, el Plan de Centro concreta y adapta a un entorno real el anterior y superior nivel, pero es la tercera esfera de las aulas la más personal y de una realidad inmediata. Es el dominio del currículo oculto, la visibilidad pendiente y otras tantas líneas que pueden, y me atrevería a decir deben, desbordar el currículo. En este sentido, la experiencia acumulada durante cuatro años en la asignatura "Complementos para la Formación Disciplinar", en nuestro caso en Historia, dentro del Máster Universitario en Profesorado de Secundaria, es la ligazón del presente artículo.

La adquisición de competencias clave con un trabajo metodológico concreto es una estrategia adecuada para visualizar el desarrollo de competencias, pues no solo se debe evaluar el resultado, sino también el procedimiento de un trabajo grupal que se beneficia de la rectificación del docente como guía o tutor. La producción de contenidos virtuales curriculares es el resultado final, pero crear estos contenidos y gestionarlos para un aprendizaje es la verdadera autonomía del docente novel, pues no solo trabaja contenidos sino la construcción del conocimiento en una comunidad de aprendizaje. El aprendizaje visual o pensamiento de imagen permite trabajar ideas por medio del 
dibujo, interrelacionar el sentido crítico con la profundización o ampliación mediante una tarea que precisa de coordinación, desarrollo del talento, liderazgo y debate (Domínguez, 2019). Además, la libre elección por parte del profesorado en formación es clave en el proyecto de generación de contenidos curriculares desde las Ciencias Sociales en el procedimiento o cómo trabajo (saber hacer). Por ende, desemboca en un banco de recursos susceptibles de posterior uso en plataformas interactivas junto a vídeos en Youtube o audios vinculados con el entorno, por ejemplo. De este modo, contenidos rígidos en un aprendizaje entre iguales, pero no cómo se trabajan, pueden ser observados de modo innovador y motivador. Un periódico digital no consiste en subir información, no basta, sino que se hace necesario contrastar o reflexionar desde la crítica.

\section{EL CÓMIC EN LAS AULAS}

La experiencia confirma la potencialidad educativa del cómic en las aulas universitarias de formación del profesorado y su futura o inmediata proyección en los espacios educativos de Secundaria. No consiste tan solo en un recurso didáctico para el aula, sino también en una herramienta innovadora en la formación inicial del profesorado y en su praxis docente y formación permanente. El cómic, tebeo o historieta, ha ganado por méritos propios un lugar destacado no solo en el panorama artístico sino también en el pedagógico. Igualmente, ha traspasado edades y gracias a la novela gráfica llega a un lector tan diverso como apasionado por un género en alza. En este sentido, la potencialidad educativa del mismo es extraordinaria desde la Educación Infantil hasta la universitaria, sin olvidar la Educación permanente como paradigma actual. En todos los espacios y contextos educativos puede ser trabajado como recurso didáctico en el ámbito de una comunidad de aprendizaje.

\section{El cómic como método}

Para la formación inicial del profesorado, en sus distintos niveles, resulta una preciada e innovadora herramienta en el uso de metodologías activas. Genera recursos de elaboración propia para el docente y por el docente o su propio alumnado. Fomenta el trabajo colaborativo y el aprendizaje visual en un marco de generosa creatividad y autonomía en las aulas. Asimismo, las líneas de trabajo son tan amplias como queramos debido a su versatilidad y actitud crítica en la variante periodística de la viñeta, por aumentar el espectro de posibilidades existente. Impreso o virtual, tradicional o innovador, reglado o propio, cualquiera de ellos tiene posibilidades en las aulas y también en la divulgación social de las Ciencias Sociales y Humanidades.

El cómic es una herramienta pedagógica en el aula, o mejor dicho en cualquier contexto educativo, pues cualquier espacio lo es. En la experiencia que analizamos, es al mismo tiempo una metodología activa que una generación de recursos. Se investiga su realización y su aplicación. No es de extrañar en un área de conocimiento como la Didáctica de las Ciencias Sociales, en la cual se investiga simultáneamente al tiempo que se desarrolla. Quizá sea esta una de sus principales valías como ciencia, junto a la formación de ciudadanos y ciudadanas capaces de desenvolverse en su 
entorno local y global, descifrar los códigos sociales que le rodean y actuar de modo crítico, responsable y comprometido con la sociedad. EI TBO es un producto de consumo de masas y como tal es necesario seleccionarlo, interpretarlo y adaptarlo al ámbito educativo. El abuso del cómic en el proceso de enseñanza-aprendizaje no viene de lo cuantitativo, sino de lo cualitativo. De mero objeto para el fomento y la comprensión lectora, creemos que debe pasar a cauce de aprendizajes. Herramienta de aprendizaje y depósito vivo de recursos didácticos a un mismo tiempo. Durante el transcurso de nuestra experiencia cumplió con esta doble función.

\section{El cómic como recurso}

La historieta tiene su génesis, obviando lenguajes visuales que se remontan a la Antigüedad, en los siglos XVIII y XIX, vinculada al nacimiento de la prensa periódica y la caricatura política (Vilches Fuentes, 2014; Blay, 2015). Pero será tras la Segunda Guerra Mundial en adelante cuando adquiera un protagonismo singular de la mano de "estilos gráficos y formas narrativas renovadoras" (Guiral, 2000, p. XIII). Como bien sintetizó Gubern, el cómic es un medio de expresión fruto de la simbiosis entre los lenguajes icónico y literario (1979, p. 105). Un lenguaje mixto que combina códigos visuales dentro del papel hegemónico de la imagen (Guzmán, 2011, p. 123). En el mundo de habla hispana, el semiólogo y polifacético intelectual argentino Massota fue uno de sus principales pioneros en su estudio teórico (1982).

Sin duda, desde entonces mucho se ha andado en la visión y uso del tebeo como herramienta de aprendizaje gracias a su comunicación verbal y no verbal. Ofrece muchas posibilidades para la inclusión y atiende a la diversidad del alumnado desde la creatividad y la cultura visual (Aured, 2014). Las imágenes significan y comunican, pero también inciden en las emociones y comportamientos (Mitchell, 2017, p. 53). Desde este punto de vista, tan relevante recurso puede ser empleado en la didáctica de la Historia a lo largo de toda la línea temporal, desde la prehistoria hasta la contemporaneidad (Grau, 2016; Vadillo, 2021). Son muchos los ejemplos al respecto, y todos señalan su virtualidad. La historieta está vinculada a fenómenos culturas y ejerce una triple función comunicadora, crítica y didáctica (Barraza, 2006, pp. 80-82). Por otra parte, además, el proceso educativo tal y como lo contemplamos en la actualidad interactúa dentro de una pluralidad sensorial y "será más pleno cuando atienda y estimule los distintos aspectos de la complejidad humana" (Trápaga, 1997, p. 54). Las conexiones no deben olvidarse, sino estimularse (Ortiz, 2014), de igual modo que desde hace años venimos insistiendo en la interdisciplinariedad.

Por todas estas razones, el cómic debe proyectarse al aula como propuesta de acción didáctica. Y debe hacerlo no solo desde los estudios literarios (Cabarcas, 2020), sino igualmente desde la Historia y demás Ciencias Sociales y Humanas, pues su potencialidad como estrategia es enorme tanto para los discentes de cualquier etapa educativa como para los docentes en formación inicial. Además, sus campos de aplicación son tan grandes como la imagen y el texto son capaces de abarcar, esto es, todos y especialmente los valores socioeducativo (Decker \& Castro, 2012). Podría parecer que entran en contradicción la historia narrativa del cómic con la innovación en el aprendizaje de la Historia, pero nada más alejado de la realidad. La secuencia, que no es más que trabajar la 
temporalidad o comprensión del tiempo histórico (Sabido, 2018; Cartes, 2020), es una herramienta valiosa para despertar interés y motivación gracias a las imágenes (Faubel, 2016, p. 316).

La comprensividad de los hechos históricos es el inicio del aprendizaje, pues la Historia se interesa más "por la significación de los hechos que por los hechos en sí mismos" (Prats y Santacana, 2001, p. 20). Y muy unida a su comprensión está la temporalidad, de ahí que el desarrollo narrativo secuencial del cómic la favorezca sobremanera y visualmente (Torres, 2001). El aprendizaje debe asumir el cambio de perspectivas temporales y metodológicas (Trepat, 2002, p. 43).

\section{METODOLOGÍA}

\section{Diseño de investigación}

La investigación educativa se implementó durante una secuencia cronológica de cuatro cursos académicos consecutivos en la Universidad de Málaga (UMA). Y se hizo tanto en el Máster Universitario en Profesorado en Educación Secundaria Obligatoria y Bachillerato, Formación Profesional y Enseñanza de Idiomas (especialidad Ciencias Sociales: Geografía e Historia y Filosofía), como en el Doble Título que añade al anterior el Máster Universitario en Filosofía, Ciencia y Ciudadanía. En el caso objeto de la presente investigación, es indistinto uno u otro, pues la asignatura comparte alumnado.

La asignatura obligatoria "Complementos para la Formación Disciplinar de Geografía, Historia y Filosofía” ( 6 créditos teóricos, en tipo de enseñanza teórica y práctica) se subdivide en su estructura interna y carga docente por cuatro áreas de conocimiento, a saber, Geografía, Filosofía, Historia del Arte e Historia. El profesorado es cambiante, procedente de las Facultades de Filosofía y Letras y de Ciencias de la Educación, si bien en este último caso se trata de profesorado con formación humanística pero con docencia en didáctica específica como es mi caso, lo cual agrega cierto rasgo diferencial. Nuestro estudio se circunscribe a su apartado de Historia. El hecho de esta multiplicidad de ramas del conocimiento concurrentes ofrece una dualidad: por una parte, la perspectiva interdisciplinaria dota de riqueza de miradas a la asignatura, cierto; por otro parte, y en sentido contrario, la carga de trabajo se acrecienta y los contenidos, métodos y tareas se solapan, como consta de las críticas del alumnado reflejadas en el Trabajo Fin de Máster (TFM), en su apartado de reflexión crítica y valoración personal sobre el propio proceso de aprendizaje profesional y sobre el programa de formación del Máster.

Módulos genérico, específico y de prácticum junto a ciclo de conferencias constituyen la formación. La asignatura pertenece al módulo específico, impartido en el segundo cuatrimestre, una vez pasado el primero y su módulo general. En este sentido, las asignaturas previas proporcionan un bagaje importante de cara al desarrollo de nuestra experiencia de investigación, pues el alumnado ha tenido ya un primer conocimiento de las metodologías educativas. En especial destaco la asignatura "Innovación docente e iniciación a la investigación educativa" (área Ciencias Sociales). Igualmente, el ciclo de conferencias le confronta con la realidad de los centros, así como el cada vez anticipado periodo de prácticas externas en los centros educativos que imparten Educación Secundaria en toda 
su tipología. Afortunadamente, esta experiencia imprescindible en su formación inicial se ha ido adelantando sustancialmente durante el transcurso de la muestra observada, respondiendo así a la petición reiterada del alumnado en sus propuestas de mejora del TFM.

Los cuatro cursos observados son: 2016/2017, 2017/2018, 2018/2019 у 2019/2020. Felizmente, no coincidió con la pandemia del coronavirus (Covid-19). El último de los cursos, en lo tocante a la impartición de Historia, pudo concluir en los límites del confinamiento oficial y la enseñanza no presencial. La enseñanza del postgrado fue presencial, pero no se realizó en la Facultad de Ciencias de la Educación, sino en el aulario López de Peñalver del mismo Campus Universitario de Teatinos, como es regular, que sí contaba con un aula específica de informática, hecho que permitió el trabajo en grupo durante horas lectivas, esto es, la observación directa del docente sobre el trabajo grupal.

El título se viene ofertando por la UMA desde el curso 2009/2010 como enseñanza oficial de Máster conforme a las disposiciones contenidas en el RD 1393/2007, de 29 de octubre. Se trata de una titulación de postgrado cuya finalidad es aportar una formación pedagógica y didáctica habilitante para el ejercicio de las profesiones de profesor/a en ESO y Bachillerato, FP y Enseñanzas de Idiomas. Ofrece capacitación profesionalizante, aspecto significativo que enhebra toda la titulación, así como su obligatoriedad para un campo laboral generoso. Además, las titulaciones con preferencia alta y media para el acceso son numerosas, lo que se traduce en un alumnado heterogéneo, cualidad que hemos contemplado desde la complementariedad.

El alumnado observado en la totalidad del ciclo corresponde al turno de tarde, lo cual no es una cuestión baladí, al contrario. Una parte del mismo no desdeñable cuantitativamente tiene reconocida su condición de alumno/a a tiempo parcial en orden a sus obligaciones laborales, o bien optaron por dicho turno en atención a otro tipo de condicionantes personales y/o familiares. En cualquier caso, aunque eran grupos heterogéneos, la edad se incrementa añadiendo un vector a considerar sobre el alto grado de madurez no solo cognitivo -que se presume en un alumnado de postgrado-, sino también en lo que respecta a las habilidades sociales. Cuestión aparte y digna de significar, es el panorama compartido mayoritariamente sobre la escasa experiencia del mundo educativo en la función de docente, manteniendo un imaginario que se retrotrae a su etapa de formación personal, que ya quedó atrás hace años. Este punto es crucial, pues tendían a reproducir el sistema por considerarlo el vigente, sin comprender de entrada los profundos cambios operados en la sociedad y su directo reflejo en las aulas.

\section{Muestra}

El alumnado fluctúa en número a lo largo del cuatrienio investigado, si bien no lo hace ostensiblemente. En total 132 alumnos y alumnas, dato relevante en lo cuantitativo. Pero este dato no resulta significativo en una segunda lectura, pues los contenidos generados desde su propia praxis se elaboraron como tarea grupal dentro del CV de la asignatura. Los recursos didácticos o materiales de elaboración propia fueron menores en cantidad como consecuencia de la agrupación del alumnado 
para su realización. Sobre la sex ratio, equilibrada. Y como aspecto importante, los grupos se conformaron autónomamente, por lo general mantuvieron la organización previa del primer cuatrimestre que había dado buenos resultados y un grado aceptable de integración y conocimientos mutuos como equipo.

El trabajo grupal sobre el empleo del tebeo como recurso didáctico en la clase de Historia en ESO y Bachillerato o Educación para Adultos se dejó en su motivo a la libre elección del alumnado. Podían trabajar un cómic o viñeta e incluso materiales de elaboración propia. El diseño de la actividad debía mantener una estructura ordinaria que abarcaba de objetivos a criterios de evaluación. Igualmente eran libres la elección de asignatura, curso o etapa dentro de los parámetros de nuestra especialidad, como también la casuística de la misma: inicial o motivadora, de desarrollo o adquisición de nuevos aprendizajes o de recapitulación o comprobación de aprendizajes. La mayor libertad del diseño obedecía al mayor estímulo de la creatividad y a responder a unos discentes diversos en formación, intereses y motivaciones. Sí se hacía necesario establecer entre los requisitos mínimos del trabajo grupal situar en el currículo el recurso e implementar una metodología y normativa acorde al nivel seleccionado. La síntesis del mismo consistía en trabajar colaborativamente el diseño de actividades formativas y el currículo habitual, pero proyectados en el recurso/herramienta cómic y centrado en la Historia, aunque en este último aspecto el profesor-tutor era flexible, tanto por convicción como por necesidad.

Esta primera aproximación al análisis de la experiencia es de naturaleza cuantitativa prioritariamente, dejamos la investigación cualitativa para un próximo estudio sobre el contenido y estructura de las propuestas del alumnado y su viabilidad entre fortalezas y debilidades. Por el momento, en espera del mencionado trabajo complementario al presente, centro la atención en la idea clave de recurso didáctico y su elaboración desde las metodologías activas en las aulas universitarias y para las aulas de Secundaria por parte del profesorado en formación inicial dentro de la especialidad de Ciencias Sociales.

\section{Tabla 1}

El cómic en el aula de Historia.

\begin{tabular}{ccc}
\hline Curso Académico & Alumnado & Recurso Didáctico \\
\hline $2016 / 2017$ & 29 & 7 \\
$2017 / 2018$ & 28 & 7 \\
$2018 / 2019$ & 40 & 9 \\
$2019 / 2020$ & 35 & 6 \\
\hline Total & 132 & 29 \\
\hline
\end{tabular}

Fuente: elaboración propia en base a la experiencia educativa cuatrienal en el MAES CCSS UMA.

En secuencia decreciente, durante el curso 2019/2020 se subieron a la herramienta CV dentro del espacio de la asignatura correspondiente a Historia un total de seis archivos digitales en formato PDF elaborados por treinta y cinco alumnos/as en la tarea grupal titulada: "El uso del cómic en el aula de Historia". Para el año 2018/2019, fueron nueve archivos correspondientes a cuarenta 
discentes. El curso 2017/2018 ofrece un resultado de siete recursos didácticos generados por un total de veintiocho alumnos/as. Y, por último, para 2016/2017, fueron igualmente siete realizados por veintinueve estudiantes. Como puede observarse de modo gráfico (véase Tabla 1), el balance es de equilibrio tanto en la cantidad de alumnado como en los recursos generados por el mismo. Esta continuidad evidencia el éxito del tipo y tamaño de agrupamientos.

\section{RESULTADOS Y DISCUSIÓN}

La orientación profesional de los títulos y las características internas de la asignatura en cuestión, han permitido cubrir los Objetivos Formativos planteados en su Plan de Estudios según Orden ECI/3858/2007, de 27 de diciembre (BOE ํㅜ 312 de 27 de diciembre), por la que se establecen los requisitos para la verificación de los títulos oficiales que habiliten para el ejercicio de las profesiones de Profesor de Educación Secundaria Obligatoria y Bachillerato, Formación Profesional y Enseñanzas de Idiomas, modificada por Orden EDU/3498/2011, de 16 de diciembre. En especial me refiero a los siguientes:

Fomentar el desarrollo de una visión global y analítica de los problemas sociales, culturales y ambientales de nuestro tiempo.

Potenciar una actitud positiva y crítica hacia el desarrollo de la identidad profesional docente.

Integrar experiencias profesionales con procesos de formación, a través de la reflexión crítica sobre todo lo que se experimenta o se aprende.

Promover el uso de los procesos de investigación en el aula como base de su desarrollo profesional.

Propiciar una formación cultural, personal, ética y social adecuada para el ejercicio de la profesión docente con el rigor científico que se debe aplicar en el ámbito de la educación de adolescentes.

Favorecer la comprensión de las relaciones existentes entre los modelos de aprendizaje, el contexto escolar y las necesarias opciones didácticas de su acción docente.

- $\quad$ Promover el reconocimiento, análisis y atención de las características diferenciales del alumnado, según su desarrollo evolutivo, contextos familiares, sociales y culturales de referencia.

- $\quad$ Conocer las competencias profesionales docentes propias de cada especialidad y su relación con las demás competencias a través de mecanismos de transversalidad.

En relación a Conocimientos y competencias:

Conocer los contenidos curriculares de las materias relativas a la especialización docente correspondiente, así como el cuerpo de conocimientos didácticos en torno a los procesos de enseñanza y aprendizaje respectivos. 
Planificar, desarrollar y evaluar el proceso de enseñanza y aprendizaje potenciando procesos educativos que faciliten la adquisición de las competencias propias de las respectivas enseñanzas, atendiendo al nivel y formación previa de los estudiantes así como la orientación de los mismos, tanto individualmente como en colaboración con otros docentes y profesionales del centro.

Buscar, obtener, procesar y comunicar información (oral, impresa, audiovisual, digital o multimedia), transformarla en conocimiento y aplicarla en los procesos de enseñanza y aprendizaje en las materias propias de la especialización cursada.

Concretar el currículo que se vaya a implantar en un centro docente participando en la planificación colectiva del mismo; desarrollar y aplicar metodologías didácticas tanto grupales como personalizadas, adaptadas a la diversidad de los estudiantes.

Diseñar y desarrollar espacios de aprendizaje con especial atención a la equidad, la educación emocional y en valores, la igualdad de derechos y oportunidades entre hombres y mujeres, la formación ciudadana y el respeto de los derechos humanos que faciliten la vida en sociedad, la toma de decisiones y la construcción de un futuro sostenible.

Adquirir estrategias para estimular el esfuerzo del estudiante y promover su capacidad para aprender por sí mismo y con otros, y desarrollar habilidades de pensamiento y de decisión que faciliten la autonomía, la confianza e iniciativa personales.

- $\quad$ Conocer los procesos de interacción y comunicación en el aula, dominar destrezas y habilidades sociales necesarias para fomentar el aprendizaje y la convivencia en el aula, y abordar problemas de disciplina y resolución de conflictos.

Fomentar el espíritu crítico, reflexivo y emprendedor.

Fomentar y garantizar el respeto a los Derechos Humanos y a los principios de accesibilidad universal, igualdad, no discriminación y los valores democráticos y de la cultura de la paz.

Desarrollar en los estudiantes habilidades de aprendizaje que les permitan continuar estudiando de un modo que habrá de ser en gran medida autodirigido o autónomo.

Más allá de los objetivos formativos o de los conocimientos y competencias alcanzados o desarrollados, cabe situar los resultados y la discusión sobre los mismos en un plano que supera la normativa y se adentra en la docencia y sus métodos para el siglo XXI. La Educación mediática incluye todos los medios de comunicación y la ingente cantidad de recursos que ofrece para la capacitación del docente y el despertar de la actitud crítica del discente. La alfabetización audiovisual es clave en el desarrollo competencial creativo de unos y de otros. Incluso la Organización de las Naciones Unidas para la Educación, la Ciencia y la Cultura (UNESCO), tomó cartas en el asunto hace ya una década (Wilson, Grizzle, Tuazon, Akyempong y Cheung, 2011). En consecuencia, el reto está bien definido.

El cómic transmite información: es un medio. Además, combina varios lenguajes o formas de 
comunicación: imagen visual y texto escrito. Puede ser una poderosa arma educativa bidireccional, así lo ha demostrado en la experiencia descrita. De ahí al relevancia de la Educación mediática. Pero han sido pocos los profesores y profesoras en formación inicial que han recibido pautas al respecto. El nuestro es un aporte más, por la vía del cómic, en la urgencia de plantear el tema de la educación mediática. Y lo es en el sentido de ampliar o repensar el ámbito educativo (Buckingham, 2005, p. 37). La formación inicial del profesorado de Ciencias Sociales y Humanidades debe hacer frente, y combatir abiertamente, la inercia escolar y sus propias resistencias a la incorporación de las Nuevas Tecnologías de modo innovador y no meramente complementario (Pérez y Varis, 2012, p. 144). En caso contrario, la herramienta no sirve, pues tan solo suple, acompaña, pero ni mejora, ni cambia. En definitiva, como acertadamente escribe Casado Salinas respecto al nuevo paradigma de los educadores:

Creo que el conocimiento de los medios y por supuesto sus implicaciones educativas deben ocupar un lugar destacado en nuestros planes de estudios si no queremos abocar a nuestros futuros egresados al fracaso más absoluto, y ello debe notarse no solo en las competencias básicas sino también en las didácticas y disciplinares. (2013, p. 53).

El debate está abierto desde una doble línea de investigación: comunicación y educación. Son vasos comunicantes y no deben ser analizados como departamentos estanco, sino interrelacionados. Ambas comparten la idea central del Espacio Europeo de Educación Superior: el impulso de "nuevos modelos educativos que renuevan metodológicamente las aulas universitarias, desarrollando estrategias didácticas activas que ponen el acento en el papel protagonista del alumno, responsable último de su proceso de aprendizaje" (Monedero y Castro, 2018, p. 70).

Desde las Ciencias de la Educación se viene desarrollando de modo pionero un modelo de alfabetización audiovisual en línea con la demandada innovación educativa. Esta misma contribución es fruto del actual Proyecto de Innovación Educativa (PIE) 19-021 "Investigar para Innovar: Desarrollo profesional docente en Didáctica de las Ciencias Sociales" (convocatoria 2019-2021), así como del PIE 17-172 "Alfabetización audiovisual para la práctica performativa" (convocatoria 2017-2019). Un significativo aporte nos parece el artículo de Triviño y Requena acerca de la alfabetización mediática en el Máster en Profesorado (MAES) coordinadamente con las prácticas externas en un Instituto de Enseñanza Secundaria (IES). El diseño de investigación educativa tuvo, a entender de la autoría que suscribimos plenamente, el tránsito de receptores a emisores audiovisuales (2019, p. 89). En nuestro caso de contenidos visuales y textuales cual el cómic representa. El alumnado elaboró o reinterpretó mensajes para trabajar en el aula, de modo autónomo en la planificación y desarrollo, colaborativo en su ejecución y de aplicación presente o futura como banco de recursos en cualquier contexto educativo creado.

La elaboración del cómic fomentó el trabajo en grupo del alumnado, el método dialógico y la empatía. Además de cuestionarse la nueva función docente y el trabajo desde metodologías innovadoras. En este sentido, las aplicaciones didácticas son muchas y así lo ha venido recogiendo la bibliografía desde hace décadas, coincidiendo con la etapa de cambio de paradigma educativo, lo 
cual no es casualidad sino que interpretamos más como causa que como consecuencia (Rollán y Sastre, 1986; Rodríguez, 1988).

No cabe duda acerca del poder dinámico de la imagen frente a la rigidez de recursos tradicionales (Vilches, 1988, p. 184). Es más, en relación al currículo oculto, el alumnado mostró una gran empatía con los actores olvidados de la Historia, recuperación de la marginación idónea en el arte secuencial del cómic según analistas consagrados (Witek, 1989; Eisner, 1993). Una Didáctica de las Ciencias Sociales para una realidad global debe partir de su renovación/innovación como cauce y no solo como meta. Los muchos investigadores que nos precedieron, así lo percibieron en especial desde el cambio de centuria (Hernández, 2002; Pagès, 2004). El alumnado demostró una aceptable predisposición para el cambio de paradigma educativo, no obstante las dificultades que eventualmente pudiera encontrar en los centros de prácticas externas para la proyección de la experiencia del aula universitaria. Un elemento quedó meridianamente definido: la función docente innovadora favorece la autonomía del aprendizaje del alumnado, al tiempo que el profesorado tiene mucho que aprender de aquel (Bárcena, 2020, p. 199).

En general, las metodologías activas desarrolladas propiciaron un proceso interactivo entre docente y discentes en el marco de nuevo estilo que convierte al alumnado en protagonista de su propio aprendizaje. Junto a la interacción horizontal, la motivación, creatividad, participación e interdisciplinariedad, destacó la generación de un pensamiento crítico en las viñetas y el valor otorgado a la comprensividad del mensaje y del conocimiento.

El Aprendizaje Basado en Proyectos llevó a dividir la clase en pequeños grupos de trabajo que investigaban un tema libre y democráticamente elegido, así como relacionado con el entorno real de la sociedad proyectada en el aula. Los objetivos del alumnado quedaron vinculados para su consecución común. Devenida en pequeña comunidad de aprendizaje, se fomentó la participación de todos los miembros mediante un proyecto conjunto sobre la base del aprendizaje dialógico y cooperativo. Esta libertad de acción del alumnado resultó clave para la buena marcha del proyecto, frente a la mera reproducción educativa (Triviño y Aragón, 2019, p. 640).

Las tareas de aprendizaje grupales favorecieron la equilibrada participación en su reparto, planificación y complementariedad. Al tratarse de formación inicial del profesorado, el docente actuó como tutor o guía, pero también proporcionó objetivos y herramientas para facilitar el trabajo como propuestas de diseño de actividades. Para retomar el carácter colaborativo, se fomentó un espacio apto para el desarrollo de habilidades y responsabilidades, tanto en al aula ordinaria como en la de informática del aulario en cuestión. Finalmente, el alumnado fijó sus propios objetivos, creó y diseñó sus propias actividades. Una mayor profundidad de la investigación cualitativa queda pendiente para un próximo artículo suplementario al presente.

\section{CONCLUSIONES}

La investigación educativa sobre el alumnado del Máster en Formación del Profesorado en la especialidad de Ciencias Sociales abarcó cuatro años consecutivos y sus características denotaron gran regularidad. La formación inicial pretendía, más de allá de la mera observación, que se adentraran en la intervención y reflexión sobre la práctica educativa real en las aulas con el eje del 
aprendizaje de la Historia. Conectar la enseñanza universitaria con sus prácticas externas de modo directo, gracias a la proyección de unos aprendizajes que tenían en las metodologías activas y colaborativas un cauce para el objetivo primordial: trabajar en grupo el diseño y puesta en práctica de la herramienta cómic con el resultado final de generar materiales de elaboración propia y contextualizada.

Se creó un contexto educativo y se gestionó el trabajo en el aula, y todo ello desde la empatía, creatividad, actitud crítica y libertad. La experiencia comprendió a 132 alumnos y alumnas y generó 29 recursos didácticos con el cómic, en una amplia tipología, como elemento central del proceso educativo en cuanto método y objetivo. La metodología de proyectos favoreció en el aula universitaria aprender a aprender en cooperación, punto básico en la formación inicial del profesorado. El alumnado, en asamblea por grupos heterogéneos, pensó un plan de acción que con posterioridad desarrolló y evaluó finalmente. Todos fueron diferentes fases de un proceso de aprendizaje organizado en tiempos y espacios, mientras que el docente facilitó el aprendizaje. Punto cardinal es que cada alumno o alumna aportaba su visión del proyecto investigado, su forma de trabajar y su compromiso personal con el mismo.

Finalizado el trabajo, cada grupo por medio de su portavoz realizó una síntesis o mapa de aprendizajes de lo planificado y elaborado para cotejar con la reunión inicial y poder así observar la progresión. Concluyó con la intervención de todos los grupos en asamblea final. Como colofón, en la medida de lo posible el alumnado vertió la actividad diseñada con el cómic en las aulas de los centros educativos del prácticum. En estos casos, la experiencia culminó su ciclo con la vuelta al aula universitaria para debatir y reflexionar sobre su resultado y plantear propuestas de mejora en base a su análisis externo e interno (DAFO) de fortalezas/oportunidades (positivo) y debilidades/amenazas (negativo). Lo cual dio lugar a un animado y participativo debate como conclusión.

La investigación cuantitativa de los datos obtenidos en la muestra sobre el uso del cómic en las aulas de Historia permite afirmar el conocimiento previo del profesorado en formación o, al menos, su buena predisposición. La investigación cualitativa explica la experiencia tras analizarla en su interpretación y evaluación. Se contemplaron como complementarias en base a reforzar sus similitudes en este proyecto, aunque somos conscientes de las diferencias. El pragmatismo dirigió todo el proceso, pues a lo cuantificable de partida, se recurrió después a valorar datos descriptivos variados, caso de las puestas en común, asambleas y transmisión de experiencias en los centros docentes desde el método analítico para encarar un problema: el alcance de la innovación educativa en las aulas por medio del recurso cómic. Las conclusiones no fueron definitivas si consideramos cada año académico por separado, pero si bien en conjunto no pueden establecer leyes -claro está-, sí tendencias. Y por último, destacamos la investigación-acción que supera la descripción para proponer como resultado vías de participación en el problema, en cuanto el alumnado como investigador era un actor del mismo proyecto.

\section{REFERENCIAS}


Aured Caravaca, A. (2014). El cuento y el cómic como estrategias didácticas para la inclusión en Educación Primaria. En C. J. Gómez Carrasco y A. Escarbajal Frutos (Eds.), Calidad e Innovación en Educación Primaria (pp. 323-331). Ediciones de la Universidad de Murcia.

Bárcena Orbe, F. (2020). El profesor en el estudio. Márgenes. Revista de Educación de la Universidad de Málaga, 1(2), 193-199. DOI: https://dx.10.24310/mgnmar.v1i2.9612

Barraza Molina, E. (2006). La historieta y su uso como material didáctico para la enseñanza de la historia en el aula. Perspectiva Educacional, Formación de Profesores, 47, 73-97.

Berenguel Aguilera, I. (2011). Las Tic's y las viñetas: una propuesta didáctica sobre los totalitarismos a través del cómic Maus. Espiral. Cuadernos del Profesorado, 4(8), 42-57.

Blay Martí, J.M. (2015). Dibujando la Historia. El cómic como recurso didáctico en la clase de Historia. Revista Supervisión 21, 36, 1-14.

Buckingham, D. (2005). Educación en medios. Alfabetización, aprendizaje y cultura contemporánea. Paidós.

Cabarcas Morales, Y. P. (2020). El cómic al aula: una didáctica narrativa. Educación y Ciudad, 38, 125-134. https://doi.org/10.36737/01230425.n38.2020.2325

Cartes Pinto, D. (2020). La periodización y la conciencia histórica en la formación del profesorado. REIDICS. Revista de Investigación en Didáctica de las Ciencias Sociales, 6, 6-23.

Casado Salinas, J.M. (2013). Educación mediática para una nueva ciudadanía. En J. J. Díaz, A. Santisteban y A. Cascajero (Eds.), Medios de comunicación y pensamiento crítico. Nuevas formas de interacción social (pp. 45-57). Universidad de Alcalá de Henares y AUPDCS.

Decker A. C. y Castro, M. (2012). Teaching History with Comic Books: A Case Study of Violence, War, and the Graphic Novel. The History Teacher, 45(2). Society for History Education.

Domínguez Rigo, M. (2019). Visual Thinking y Creatividad. En M. Larragueta Arribas e I. Ceballos Viro (Eds.), Educación y Transformación Social y Cultural (pp. 421-427). Editorial Universitas.

Eisner, W. (1993). Invisible people. Kitchen Sink Press.

Faubel, V. S. (2016). El uso del cómic y la narrativa gráfica como estrategia didáctica en el aula de Historia y Ciencias Sociales. En J. Lluch-Prats, J. Martínez y L. C. Souto (Eds.), Las batallas del cómic. Perspectivas sobre la narrativa gráfica contemporánea (pp. 314-333). Anejos de Diablotexto Digital

Grau Gadea, S. (2016). El cómic como recurso didáctico para el aprendizaje de la Prehistoria en los museos. En J. Abarca Pérez (Ed.), Prehistoria y cómic (pp. 194-218). Museo de Prehistoria 
de Valencia.

Gubern, R. (1979). El lenguaje de los cómics. Península

Guzmán López, M. (2011). El cómic como recurso didáctico. Pedagogía Magna, 10, 122-131.

Guiral, A. (2000). Veinte años de cómic. Vicens Vives.

Hernández Cardona, X. (2002). Didáctica de las Ciencias Sociales, geografía e historia. Editorial Graó.

Massota, O. (1982). La historieta en el mundo moderno. Paidós.

Mitchell, W. J. T. (2017). ¿Qué quieren las imágenes? Sans Soleil Ediciones.

Monedero Morales, C. del R. y Castro Higueras, A. (2018). Un proyecto de aplicación de la clase invertida en las Ciencias de la Comunicación. En REDINE (Ed.), Innovative Strategies for Higher Education in Spain (pp. 69-79). Adaya Press.

Onieva López, J. L. (2015). El cómic online como recurso didáctico en el aula. Webs y Apps para aplicaciones móviles. Huarte de San Juan. Filología y Didáctica de la Lengua, 15, 105-127.

Ortiz Hernández, F. J. y Vidal-Martín-Toledano, J. (2014). Música y cómic. Relaciones didácticas y artísticas. En M. T. Tortosa Ybáñez, J. D. Álvarez Teruel y N. Pellín Buades (Coords.), XII Jornadas de Redes de Investigación en Docencia Universitaria (pp. 1016-1029). Instituto de Ciencias de la Educación Universidad de Alicante.

Pagès i Blanch, J. (2004). Enseñar a enseñar Historia: la formación didáctica de los futuros profesores de Historia. En E. Nicolás y J. A. Gómez (Coords.), Miradas a la Historia. Reflexiones historiográficas en recuerdo de Miguel Rodríguez Llopis (pp. 155-178). Universidad de Murcia.

Pérez Tornero, J. M. y Varis, T. (2012). Alfabetización mediática y nuevo humanismo. Editorial UOC.

Prats, J. y Santacana, J. (2001). Principios para la enseñanza de la Historia. En J. Prats (Ed.), Enseñar Historia: Notas para una didáctica renovadora (pp. 13-34). Consejería de Educación, Ciencia y Tecnología de la Junta de Extremadura.

Rodríguez Diéguez, J. L. (1988). El cómic y su utilización didáctica. Los tebeos en la enseñanza. Gustavo Gili.

Rollán Méndez, M. y Sastre Zarzuela, E. (1986). El cómic en la escuela. Aplicaciones didácticas. Instituto de Ciencias de la Educación Universidad de Valladolid.

Sabido Codina, J. (2018). La temporalidad como núcleo base de la construcción conceptual del 
pensamiento histórico. En A. López-García y P. Miralles Martínez (Eds.), Nuevas líneas y tendencias de investigación en Educación histórica (pp. 105-115). Ediciones de la Universidad de Murcia.

Torres Bravo, P. A. (2001). Enseñanza del tiempo histórico: historia, kairos y cronos. Una mirada didáctica para el aula de la ESO. Ediciones de la Torre.

Trápaga Marsical, F. (1997). ¡Escuela e imagen, hoy! Comunicar. Revista de Educación en Medios de Comunicación, 8, 49-55.

Trepat, C. A. (2002). Fundamentos teóricos para una didáctica del tiempo en las Ciencias Sociales. En C. A. Trepat y P. Comes (Eds.), El tiempo y el espacio en la Didáctica de las Ciencias Sociales (pp. 11-45). Editorial Graó.

Triviño Cabrera, L. y Requena Palacios, C. (2019). Investigación e innovación educativa desde el Máster de Formación del Profesorado de Ciencias Sociales a las prácticas curriculares en Educación Secundaria. Contextos educativos. Revista de Educación, 23, 83-99. http://doi.org/10. 18172/con. 3513

Triviño Cabrera, L. Y Aragón Aranda, G. (2019). La tertulia ciudadana dialógica como metodología crítica en la enseñanza de las Ciencias Sociales. En M. J. Hortas, A. Dias y N. de Alba (Eds.), Enseñar y aprender Didáctica de las Ciencias Sociales: la formación del profesorado desde una perspectiva sociocrítica (pp. 639-648). Ediciones ESE Instituto Politécnico de Lisboa y AUPDCS.

Vadillo Muñoz, J. (2021). El cómic y la enseñanza de la Historia Contemporánea. Didácticas específicas, 24, 39-62.

Vilches, L. (1988). Teoría de la imagen, pedagogía de la imagen. En J. L. Rodríguez (Ed.), Educación y comunicación (pp. 183-206). Paidós.

Vilches Fuentes, G. (2014). Breve historia del cómic. Nowtilus.

Wilson, C., Grizzle, A., Tuazon, R., Akyempong, K. y Cheung, C. (2011). Alfabetización Mediática e Informacional. Curriculum para Profesores. UNESCO.

Witek, J. (1989). Comic books and history. The narrative art of Jack Jackson, Art Spiegelman, and Harvey Pekar. University Press of Mississippi. 